James Madison University JMU Scholarly Commons

Masters Theses

The Graduate School

Summer 2016

\title{
The effect of the CYP1A2 -163 C >A polymorphism on the metabolism of caffeine and effect on performance
}

Gabrielle E. Giersch

James Madison University

Follow this and additional works at: https://commons.lib.jmu.edu/master201019

Part of the Sports Sciences Commons

\section{Recommended Citation}

Giersch, Gabrielle E., "The effect of the CYP1A2 -163 C>A polymorphism on the metabolism of caffeine and effect on performance" (2016). Masters Theses. 458.

https://commons.lib.jmu.edu/master201019/458

This Thesis is brought to you for free and open access by the The Graduate School at JMU Scholarly Commons. It has been accepted for inclusion in Masters Theses by an authorized administrator of JMU Scholarly Commons. For more information, please contact dc_admin@jmu.edu. 
The Effect of the CYP1A2 -163 C>A Polymorphism on the Metabolism of Caffeine and Effect on Performance

Gabrielle Giersch

A thesis submitted to the Graduate Faculty of

JAMES MADISON UNIVERSITY

in partial fulfillment of the requirements for the degree of

Master of Science

Department of Kinesiology

August 2016

FACULTY COMMITTEE:

Committee Chair: Christopher J. Womack, Ph.D.

Committee Members/ Readers:

Nicholas D. Luden, Ph.D.

Michael J. Saunders, Ph.D.

Trent A. Hargens, Ph.D. 


\section{Acknowledgements}

I would like to thank Dr. Christopher Womack for being the chair to my thesis and always being willing to give me all the help I needed. It always took me a little extra time to get where we needed this to go and I truly appreciate your patience, guidance, and support.

Thank you to the rest of my committee, Dr. Trent Hargens, Dr. Nicholas Luden, and Dr. Michael Saunders for the support and help you've provided throughout this process.

I would like to thank Hannah Daley and Dr. Christine Hughey for the analysis of the metabolite samples. Hannah put in a lot of time and effort on this project, and without her, it truly would not have been possible.

Thank you to my parents and my family for supporting me throughout my entire life; I truly don't know where I'd be without all of their love and support.

To all the friends and colleagues here at JMU, especially Jamey Boyett, without whom this project wouldn't have been so successful. Ryan Martin, Mark Pataky, Alec McKenzie, Matthew Scott, Jake Ridings, Jess Ehrbar, Paul Roberson, Tori Corapi, John Chase, Dan Valcicak, Erin Horil thank you so much for your friendship and support. Also thank you to Andrew Marquez, David Pumphrey, and Jordan Parker for their help and dedication with assisting in data collection.

I would also like to thank all of the subjects and participants who volunteered their time to participate, without whom, this project definitely wouldn't have been possible. 


\section{Table of Contents}

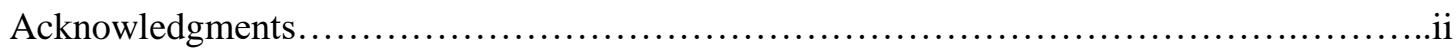

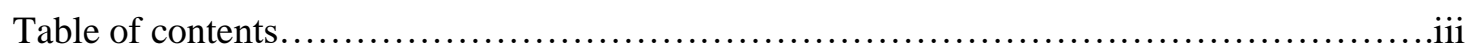

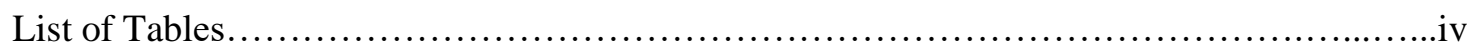

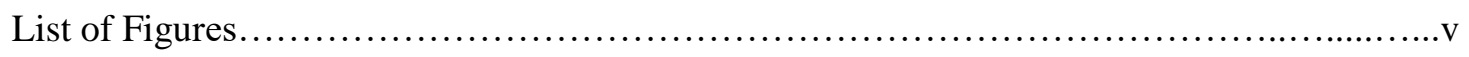

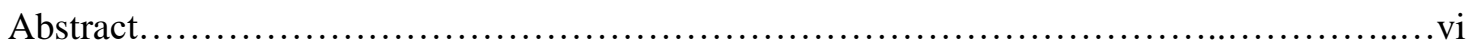

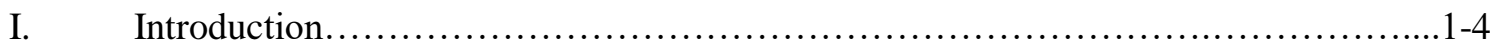

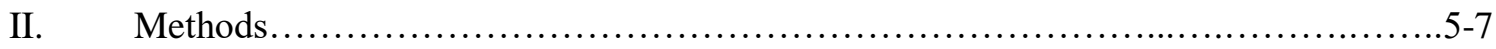

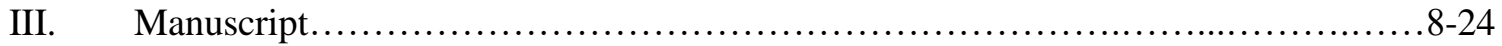

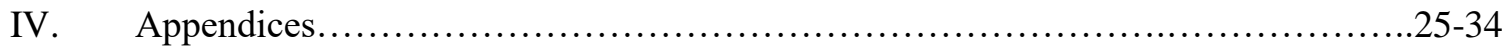

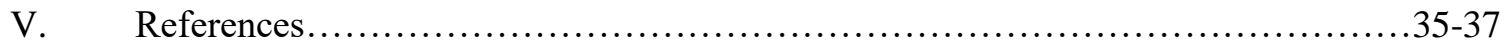




\section{List of Tables}

Table 1. Caffeine, metabolite, and metabolite ratio values..............................22 


\section{List of Figures}

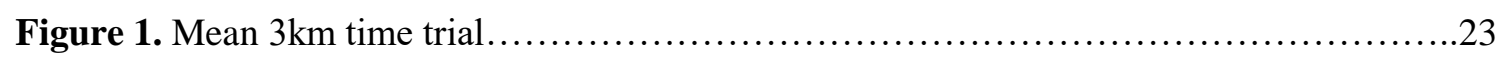

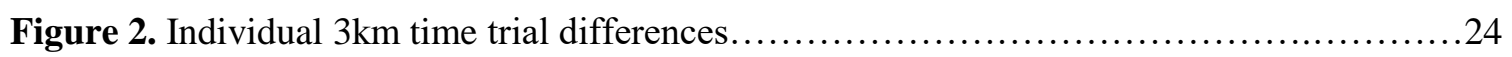




\begin{abstract}
Prior studies from our laboratory suggest that the $-163 \mathrm{C}>\mathrm{A}$ polymorphism of the Cytochrome P450 (CYP1A2) gene influences the ergogenic effect of caffeine. Although this polymorphism has been known to influence the inducibility of hepatic CYP1A2 and the rate of caffeine metabolism, levels of caffeine and/or metabolites have never been reported in these aforementioned studies $(1,12,16)$. Thus, a mechanistic link between the polymorphism and the ergogenic effect of caffeine is lacking. The purpose of this study was to determine if the CYP1A2 polymorphism affected caffeine metabolism between the genotypes (AA homozygotes and C allele carriers). Twenty male subjects were recruited for this study. Subjects participated in two $3 \mathrm{~km}$ cycling time trials with placebo (all-purpose flour) and caffeine $(6 \mathrm{mg} / \mathrm{kg}$ body weight anhydrous caffeine) supplementation. "Slow metabolizers" were characterized as possessing a "C" allele on the first intron of that gene (grouped AC heterozygotes, and CC homozygotes), and "fast metabolizers" were those who were homozygous for the A allele. C allele carriers had significantly higher serum caffeine after one hour $(\mathrm{C}$ allele carriers $=14.2 \pm 1.8 \mathrm{ppm}, \mathrm{AA}$ homozygotes $=11.7 \pm 1.7 \mathrm{ppm}$ ). While there was a main effect for caffeine ingestion on time trial performance, there was no caffeine $\mathrm{x}$ genotype interaction (C allele carriers: Placebo $=297 \pm$ $20.8 \mathrm{sec}$, Caffeine $=292 \pm 20 \mathrm{sec} ;$ AA homozygotes: Placebo $=318.3 \pm 34.5 \mathrm{sec} ;$ Caffeine $=$ $307.9 \pm 21.9 \mathrm{sec})$. Results from this study suggest that $\mathrm{C}$ allele carriers have higher serum caffeine after one hour than AA homozygotes, consistent with the assertion that $\mathrm{C}$ allele carriers metabolize caffeine slower. These findings do not support a genetic influence on the ergogenic effect of caffeine in a $3 \mathrm{~km}$ cycling trial.
\end{abstract}

Keywords: caffeine, cycling performance, metabolite 


\section{Chapter 1}

\section{Introduction}

\section{$\underline{\text { Caffeine and performance }}$}

The ergogenic effects of caffeine have been extensively studied over the past four decades. Although many studies have observed that caffeine improves performance, the extent of this ergogenic benefit can vary with respect to type of exercise, individual responses, and dosage $(3,11,16,34)$. Improvement in performance has been seen in endurance, resistance and high intensity exercise $(3,11,16,18,33,34)$. Furthermore, caffeine doses between 3 and $9 \mathrm{mg} / \mathrm{kg}$ of body weight have been effective $(3,33)$. Up to $31 \%$ improvements in endurance performance have been observed with dosages ranging between $3-6 \mathrm{mg} / \mathrm{kg}$ of body weight $(\mathrm{BW})(4,16,34)$. Several theories exist to explain the ergogenic effect of caffeine including increased lipolysis, free-fatty acid mobilization, and muscular force $(3,5,9,10,14)$.

It is commonly believed that caffeine competes with adenosine, a compound of similar chemical structure, to bind with adenosine receptors. When adenosine binds, it induces relaxation of the vascular smooth muscle, leading to vasodilation, decreased neuronal firing and release of neurotransmitters (NTs) (13). This reduces vasoconstriction and the shunting of the blood from the splanchnic region to the muscles (13). However, when caffeine is bound to adenosine receptors, adenosine is not able to bind, thus not able to exert this effect. Caffeine metabolites also have an affinity for caffeine receptors (13). With training, adenosine receptor density increases, exponentially increasing the potential effect of caffeine (13).

\section{Anaerobic Exercise}

Several studies have examined the effect of caffeine supplementation on short-duration high-intensity exercise and observed improvements in time, speed, and work performed (7, 12, 
$15,17,30)$. Glaister et. al observed a $1.4 \%$ improvement in performance of twelve sets of thirtymeter sprints with caffeine supplementation at $5 \mathrm{mg} / \mathrm{kgBW}$ (15). Carr et. al found a dosage of $6 \mathrm{mg} / \mathrm{kgBW}$ elicited a 1.1-1.6\% observed improvement in sprint time with caffeine supplementation (7). Furthermore, Schneiker et. al also observed an improvement in total work in four-second sprints, with a dosage of $6 \mathrm{mg} / \mathrm{kg}$ of body weight (30). An increase in anaerobic power has also been observed with caffeine supplementation. Anselme et. al observed an increase in maximal anaerobic power $\left(\mathrm{W}_{\max }\right)$ during a series of maximal sprints with $250 \mathrm{mg}$ ingested caffeine (2). Time to exhaustion has also been observed to increase with caffeine supplementation in the short-duration/high-intensity domain $(11,12,16,17,19)$.

\section{Endurance Performance}

The ergogenic effect of caffeine on endurance performance has also been observed in many studies at dosages ranging between $3-6 \mathrm{mg} / \mathrm{kgBW}(3,9,17,18,19,22,25)$. Improved endurance performance has been observed across different modalities, including running and cycling (the two most often investigated). Jackman et. al observed a $20 \%$ increase in maximal cycling time to fatigue with caffeine supplementation (23). Bridge et. al found a $1.2 \%$ increase in $8 \mathrm{~km}$ run time of with $3 \mathrm{mg} / \mathrm{kgBW}$ caffeine dose (4). McNaughton also observed an increase in cycling distance with $6 \mathrm{mg} / \mathrm{kgBW}$ caffeine supplementation during three separate one-hour time trials (25). The effect on endurance performance appears to be greatest at moderate dose, between $3-6 \mathrm{mg} / \mathrm{kgBW}$, propagating an improvement ranging from $1.2 \%$ to $31 \%(3,4,11,23,25)$.

\section{Genetic Influence of Caffeine Metabolism}

Cytochrome P450 1A2 (CYP1A2) is a hepatic enzyme is primarily responsible for caffeine metabolism. The CYP1A2 enzyme breaks down caffeine into three primary metabolites: paraxanthine, theophylline, and theobromine $(15,22,24)$. These metabolites are thought to have an ergogenic effect on performance by competitively binding to adenosine receptors and 
inhibiting the action of adenosine, similar to the action of caffeine (13). In fact, these metabolites are thought to potentially have a higher affinity for the adenosine receptors than caffeine, potentially making the effect of caffeine's metabolites more potent than the effect of caffeine itself $(13,14,24)$. The three metabolites have unique characteristics for their proposed effect on performance (3). Paraxanthine, the most common metabolite of caffeine, stimulates lipolysis; theophylline stimulates smooth muscle relaxation leading to increased vasodilation; and theobromine increases vasodilation and urine volume (3).

A single-neucleotide $(\mathrm{A} / \mathrm{C})$ polymorphism in intron 1 of the CYP1A2 gene affects the rate of caffeine metabolism in the liver $(14,29)$. This polymorphism leads to higher inducibility of the enzyme in AA homozygotes over C allele carriers (29). Sasche et. al observed a significant difference across genotypes for plasma caffeine in a group of smokers, with A/A homozygotes having significantly higher metabolic activity. This study recognized the increased prevalence of the polymorphism and the varying affects it caused across genotypes, and in smokers and nonsmokers (29). Several studies have since examined this polymorphism and have proposed that A/A homozygotes are fast metabolizers of caffeine in contrast to $\mathrm{C}$ allele carriers (8).

\section{The CYP1A2 polymorphism and health outcomes}

This polymorphism and its effect on caffeine metabolism have been associated with caffeine's influence on the risk of myocardial infarction, hypertension, and lower bone mineral density $(8,19,26)$. In 1,805 subjects, both with and without prior acute myocardial infarction (MI), C allele carriers had an increased risk for non-fatal myocardial infarction with caffeine ingestion; a risk not evident in A/A homozygotes. Via multivariate analysis, odds ratios were determined to be $1.19(\mathrm{~A} / \mathrm{C})$ and $1.55(\mathrm{C} / \mathrm{C})$ compared to 1.00 in A/A homozygotes (8). Palatini et. al observed an increased risk of hypertension for slow caffeine metabolizers (C allele carriers) with or without coffee (caffeine) ingestion (26). In a group of 717 elderly men and women, A/A 
homozygotes had a higher risk for lower bone mineral density (BMD) with high caffeine consumption in comparison to $\mathrm{C}$ allele carriers. This study assessed BMD by Dual-energy X-ray absorptiometry (DXA) of the proximal femur (20). Thus the possession of a $\mathrm{C}$ allele at intron 1 increases risk for acute MI, decreases risk for lower BMD, and decreases inducibility of the CYP1A2 enzyme $(8,20,21,29)$.

The CYP1A2 polymorphism's effect on the ergogenic properties of caffeine

Studies from our laboratory have observed differences in ergogenic effect of caffeine between the aforementioned genotypes. It has been hypothesized that the different genotypes' metabolize caffeine at different rates, which leads to a variance in caffeine response. In a group of competitive cyclists, Womack et. al observed a more pronounced ergogenic effect in A/A homozygotes, with an increased 40k time trial performance of 3.8 minutes as compared to a 1.3 minute improvement in C allele carriers (35). In contrast, Pataky et. al observed a larger increase in $3 \mathrm{k}$ time trial performance in $\mathrm{C}$ allele carriers compared to over A/A homozygotes in 38 recreationally trained cyclists (27). Conflicting with both studies, Algrain et al observed no differences in a 15-minute cycling performance between genotypes in 20 "modestly fit" subjects (1). Thus, the effect of the CYP1A2 polymorphism on the ergogenic response to caffeine is unclear. Furthermore, while the aforementioned differences across genotypes in prior studies were assumed to be due to differences in caffeine metabolism, it has never been directly measured in conjunction with a study on caffeine supplementation and exercise performance. Therefore, the purpose of this study is to determine the effect that the CYP1A2 polymorphism has on caffeine metabolism and the ergogenic effect of caffeine. We hypothesize that $\mathrm{C}$ allele carriers will have increased performance, increased caffeine concentrations and decreased caffeine metabolites compared to AA homozygotes. 


\section{Chapter 2}

\section{Methodology}

\section{Subjects}

Twenty healthy male participants will be recruited for this study. All subjects will provide written consent before participating. It is estimated that approximately $45 \%$ will be AA homozygotes and $55 \%$ will possess a $\mathrm{C}$ allele $(25,33)$. Recruitment will take place through James Madison University's campus and community organizations and within the Harrisonburg community. The Institutional Review Board at James Madison University approved this study.

\section{Data Collection}

\section{Descriptive Measures}

Prior to the performance trials, subjects will perform a $\mathrm{VO}_{2 \max }$ test on a Velotron ${ }^{\mathrm{TM}}$ cycle ergometer to obtain descriptive data. Subjects will warm-up on a treadmill at $3.5 \mathrm{mph}$ for five minutes. Beginning wattage varied between trained and untrained individuals, with trained individuals beginning at $150 \mathrm{~W}$ and increasing by $25 \mathrm{~W}$ every minute, and untrained individuals beginning at $100 \mathrm{~W}$ with identical increases every minute. After the test began the intensity was increased by 15 watts every minute until the subject was too fatigued to continue. Metabolic data was collected continuously using a MOXUS® Modular $\mathrm{VO}_{2}$ system. $\mathrm{VO}_{2 \max }$ was determined using the highest mean 30 -sec value.

\section{Supplementation}

In a crossover, double-blind fashion, the subjects will be provided with caffeine treatment (6mg/kg of body weight of anhydrous caffeine capsule) or placebo (all-purpose flour capsule). 
Supplementation ingestion will take place in the laboratory one hour prior to the start of the performance trials.

\section{Familiarization Trial}

The subjects will undergo two $3 \mathrm{~km}$ time trials on a Velotron ${ }^{\mathrm{TM}}$ cycle ergometer as familiarization trials prior to their first performance trial. Subjects will be instructed to cycle the distance as fast as possible for both trials, identical to the protocol for the performance trials with the exception of supplement (treatment) ingestion.

\section{Performance Trials}

Subjects will complete a total of four performance trials at least three days apart (two morning and two afternoon trials). Morning and afternoon trials will be completed between the hours of 6:00am-10:00am and between 4:00pm-8:00pm respectively with at least eight hours between individual subjects' morning and afternoon trials. Morning and afternoon trials will be analyzed separately for multiple studies. A venous blood draw will be taken upon entry to the laboratory and another prior to their exercise trial (60 minutes after ingestion of treatment or placebo). Subjects will then perform a 3k-time trial on a Velotron cycle ergometer.

Trials will be repeated in a crossover design for treatment and time of day with trials separated by at least three days in a double-blind fashion.

\section{Blood Analysis}

Blood will be drawn from an antecubital vein into serum vacutainer tubes. Samples will be spun in a refrigerated centrifuge (AccuSpin $\left.{ }^{\mathrm{TM}}\right)$ at $1500 \mathrm{rpm}$ for 20 minutes. The serum will be extracted and stored in a $-80^{\circ} \mathrm{C}$ freezer until analysis. 
Serum caffeine (CAF), paraxanthine (PX), theobromine (TB), and theophylline (TP) will be analyzed using Mass Spectrometry as described previously (26).

DNA will be obtained from whole blood samples using commercially available kits (GE Healthcare). The Department of Nutritional Sciences University of Toronto will perform genotyping using restriction fragment length polymorphism-polymerase chain reaction as described previously (7).

\section{Statistical Analysis}

$3 \mathrm{~km}$ time, plasma caffeine and its metabolites (PX, TB, TP), as well as the paraxanthine:caffeine ration will be compared between genotypes (AA homozygotes and C-allele carriers) in both trials using paired t-tests. T-tests will also be used for $3 \mathrm{~km}$ performance (treatment, genotype) and caffeine metabolism (treatment, time, genotype). Post-hoc testing will be performed using independent and dependent t-tests with a Bonferonni correction. A priori significance will be set at $\mathrm{P}<0.05$. 
Chapter 3

Manuscript 
The Effect of the CYP1A2 -163 C>A Polymorphism on the Metabolism of Caffeine and Effect on Performance

Authors: Gabrielle E. W. Giersch, James C. Boyett, Trent A. Hargens, Nicholas D. Luden, Michael J. Saunders, Hannah Daley, Christine A. Hughey, Ahmed El-Sohemy, Christopher J. Womack

Institution: James Madison University, Harrisonburg, Virginia 22802

Contacts: Gabrielle E. W. Giersch, gierscge@dukes.jmu.edu

James C. Boyett, boyettjc@dukes.jmu.edu

Trent A. Hargens, hargenta@jmu.edu

Nicholas D. Luden, ludennd@jmu.edu

Michael J. Saunders, saundemj@jmu.edu

Hannah Daley, hannah.daley@emu.edu

Christine A. Hughey, hugheyca@jmu.edu

Ahmed El-Sohemy, a.el.sohemy@utoronto.ca

Christopher J. Womack, womackcx@jmu.edu

Address of Correspondence

Christopher J. Womack, Ph.D.

Department of Kinesiology

James Madison University

Harrisonburg VA, 22807

Phone: (540) 568-6145

Email: womackcx@jmu.edu 


\begin{abstract}
Prior studies from our laboratory suggest that the $-163 \mathrm{C}>$ A polymorphism of the Cytochrome P450 (CYP1A2) gene influences the ergogenic effect of caffeine. Although this polymorphism has been known to influence the inducibility of hepatic CYP1A2 and the rate of caffeine metabolism, levels of caffeine and/or metabolites have never been reported in these aforementioned studies $(1,12,16)$. Thus, a mechanistic link between the polymorphism and the ergogenic effect of caffeine is lacking. The purpose of the present study was to determine if the CYP1A2 polymorphism affected caffeine metabolism and subsequent performance between the genotypes (AA homozygotes and $\mathrm{C}$ allele carriers). Twenty male subjects were recruited for this study. Subjects participated in two $3 \mathrm{~km}$ cycling time trials with placebo (all-purpose flour) and caffeine $(6 \mathrm{mg} / \mathrm{kg}$ body weight anhydrous caffeine) supplementation. "Slow metabolizers" were characterized as possessing a "C" allele (grouped AC heterozygotes, and CC homozygotes), and "fast metabolizers" were those who were homozygous for the A allele. C allele carriers had significantly higher serum caffeine after one hour $(\mathrm{C}$ allele carriers $=14.2 \pm 1.8 \mathrm{ppm}, \mathrm{AA}$ homozygotes $=11.7 \pm 1.7 \mathrm{ppm}$ ). While there was a main effect for caffeine ingestion on time trial performance, there was no caffeine $\mathrm{x}$ genotype interaction (C allele carriers: Placebo $=297 \pm$ $20.8 \mathrm{sec}$, Caffeine $=292 \pm 20 \mathrm{sec} ;$ AA homozygotes: Placebo $=318.3 \pm 34.5 \mathrm{sec} ;$ Caffeine $=$ $307.9 \pm 21.9 \mathrm{sec})$. Results from this study suggest that $\mathrm{C}$ allele carriers have higher serum caffeine after one hour than AA homozygotes, consistent with the assertion that $\mathrm{C}$ allele carriers exhibit slower caffeine metabolism. These findings do not support a genetic influence on the ergogenic effect of caffeine in a $3 \mathrm{~km}$ cycling trial.
\end{abstract}




\section{Introduction}

The effect of caffeine on exercise performance has been thoroughly documented in a variety of activities $(2,5,8,9)$. Caffeine's ergogenic effect is proposed to be related to its affinity for adenosine receptors. When adenosine is not bound to its receptors, the parasympathetic effect of adenosine is impaired, causing an increase in sympathetic activity (7). Caffeine's metabolites: paraxanthine (PX), theobromine (TB), and theophylline (TP) also have an affinity for adenosine receptors, and have been theorized to have a higher affinity for those receptors than caffeine (7). Cytochrome P450 (CYP1A2) is the enzyme responsible for caffeine metabolism in the liver and converts it to the three major metabolites listed above.

A single-nucleotide polymorphism (CYP1A2 -163 C > A) significantly affects the inducibility of this enzyme such that caffeine metabolism is faster in AA homozygotes and slower in C allele carriers $(11,13)$. Previous studies from this laboratory have observed differences in performance between these genotypes. Womack et al observed that caffeine improved $40 \mathrm{~km}$ cycling performance to a greater extent in AA homozygotes than $\mathrm{C}$ allele carriers (both $\mathrm{A} / \mathrm{C}$ heterozygotes and CC homozygotes) in 35 trained male cyclists (16). Conversely, Pataky et al found that $\mathrm{C}$ allele carriers observed a greater ergogenic benefit than AA homozygotes in a $3 \mathrm{~km}$ cycling time trial (12). Algrain et al did not observe any significant differences in the effect of caffeine on a 15-minute performance trial between the genotypes and there was no main effect of caffeine observed (1).

Clearly, the prior findings on the effect of this polymorphism on the ergogenic effect of caffeine are equivocal. Furthermore, none of these prior studies have reported the influence of the polymorphism on caffeine metabolism. Thus a mechanistic link between the polymorphism and the ergogenic benefit of caffeine is lacking. The aims of this study were to determine if the CYP1A2 -163 A/C polymorphism influenced caffeine metabolism and subsequent $3 \mathrm{~km}$ cycling 
performance in young, healthy, male subjects. We hypothesized that $\mathrm{C}$ allele carriers would perform better in the $3 \mathrm{~km}$ time trial as previously noted from the Human Performance Lab (12) and that $\mathrm{C}$ allele carriers would have higher serum caffeine concentrations and lower serum caffeine metabolite concentrations compared to the AA homozygotes. 


\section{Methods}

Subjects: Twenty male subjects between the ages of 18-45 were recruited from the James Madison University and greater Harrisonburg area. The study was approved by James Madison University and all subjects gave informed consent prior to starting the study. This study was conducted in a double-blind fashion. Subjects reported to James Madison University's Human Performance Lab for all visits, including a graded cycling test to determine $\mathrm{VO}_{2 \max }$, and four $3 \mathrm{~km}$ cycling time trials (two familiarization trials, and two experimental trials).

$\underline{\mathrm{VO}}_{2 \max }:$ All subjects participated in a graded exercise test on a Velotron cycle ergometer. Metabolic data was collected on a Moxus Modular $\mathrm{VO}_{2}$ system. Starting wattage was $150 \mathrm{~W}$ for trained subjects, and $100 \mathrm{~W}$ for untrained subjects, $25 \mathrm{~W}$ were added every minute until volitional exhaustion. Heart rate, $\mathrm{RPE}, \mathrm{W}$, and $\mathrm{VO}_{2}$ was recorded every minute and $\mathrm{VO}_{2 \max }$ was considered the largest minute-average. Subjects had an average $\mathrm{VO}_{2 \max }$ of $57.2 \mathrm{ml} / \mathrm{kg} / \mathrm{min}$.

$\underline{3 \mathrm{~km} \text { Time Trials: Familiarization trials consisted of a 5-minute warm-up walk at } 3.5 \mathrm{mph} \text { on a }}$ treadmill. After the warmup, subjects performed a $3 \mathrm{~km}$ time trial in order to reduce possible learning effects during repeated performance trials. All cycling trials were performed on a Velotron cycle ergometer.

Performance trials were conducted between the hours of 6:00am and 10:00am where supplementation was provided in a double-blind randomized order for each subject. Subjects were at least 4 hours post-prandial and abstained from caffeine and alcohol for 12 and 24 hours respectively prior to each trial. Diet and physical activity logs were collected from each subject prior to each trial and subjects were instructed to replicate diet and exercise logs as closely as possible. Supplementation for subjects was either $6 \mathrm{mg} / \mathrm{kg}$ body weight of anhydrous caffeine (CAF) or all-purpose flour (PLA) in two gel capsules. A baseline venous blood draw was obtained prior to treatment for each subject, then a post-treatment blood draw was taken one hour 
after supplement ingestion. Subjects then performed a $3 \mathrm{~km}$ cycling time trial. Subjects were given information about distance traveled, and distance remaining during the trials but were blinded to time. This study was also part of a larger study where subjects participated in afternoon $3 \mathrm{~km}$ time trials on separate days.

Genotyping: DNA was obtained from whole blood samples using commercially available extraction kits (illustra blood genomicPrep mini spin kit; GE Healthcare; Pittsburgh, PA). Subjects were genotyped as previously described and grouped as AA homozygotes or C allele carriers (3). Due to the similarities in metabolism in all $\mathrm{C}$ allele carriers, as previously discussed $(4,13)$, we remained consistent with prior research $(1,4,16)$ and combined CC homozygotes and heterozygotes into one group.

Caffeine/Metabolite Assays: $\quad$ Serum was collected from the blood samples by centrifuging samples (AccuSpin ${ }^{\mathrm{TM}}$ ) at 2500 rpm for 15 minutes. Serum was stored in a -80 degree $\mathrm{C}$ freezer until thawed and prepared for mass spectrometry analysis. Mass spectrometry analysis was performed in the Chemistry Department at James Madison University.

Statistical Analysis: Repeated measures analysis of variance was calculated to determine differences between caffeine and placebo treatment for individuals. Pearson correlation coefficients were calculated between the caffeine metabolite concentrations, ratio, and improvements in performance. 


\section{Results}

There were eight AA homozygotes (40\%), eight AC heterozygotes (40\%), and four CC homozygotes (20\%). Average performance times per group and individual performances within both trials are shown in Figures 1 and 2. Figure 1 shows mean differences between groups in $3 \mathrm{~km}$ time trial performance. There was a main effect $(\mathrm{P}<0.05)$ for caffeine on time trial performance in that caffeine resulted in an average improvement in the time trial of $7.11 \pm 13.91$ $\sec (2.2 \%)$. Figure 2 shows individual performances for $3 \mathrm{~km}$ time trials with caffeine and placebo supplementation. Any points that fall below the line of identity in this figure show an improvement in performance. There were four and five AA homozygotes and $\mathrm{C}$ allele carriers that improved performance respectively. There was also a strong trend $(\mathrm{P}=0.054)$ for caffeine to improve average power output during the time trial $($ Placebo $=246.35 \pm 56.41 \mathrm{~W}$, Caffeine $=$ $258.05 \pm 50.65 \mathrm{~W})$. There was not a significant caffeine $\mathrm{x}$ genotype interaction, as the AA homozygotes $($ Placebo $=318.28 \pm 34.81 \mathrm{sec}$, Caffeine $=307.92 \pm 21.89 \mathrm{sec})$ and $\mathrm{C}$ allele carriers $($ Placebo $=296.98 \pm 20.82 \mathrm{sec}$, Caffeine $=292.03 \pm 20.01 \mathrm{sec})$ had similar responses to caffeine. Similarly, Power output (W) during the $3 \mathrm{~km}$ cycling time trials was not different $(\mathrm{P}>$ 0.05 ) between groups [AA homozygotes (Placebo $=223.50 \pm 58.26 \mathrm{~W}$, Caffeine $=235.00 \pm$ 40.36W); C allele carriers (Placebo $=261.58 \pm 49.62 \mathrm{~W}$, Caffeine $=273.42 \pm 50.98 \mathrm{~W})]$.

Average serum caffeine, caffeine metabolites, the paraxanthine:caffeine ratio and the metabolite:caffeine ratio for both genetic groups one hour after supplementation are shown in Table 1. C allele carriers $(14.17 \pm 1.82 \mathrm{ppm})$ had significantly $(\mathrm{P}<0.05)$ higher serum caffeine than AA homozygotes $(11.65 \pm 1.79 \mathrm{ppm})$. There were no differences $(\mathrm{P}>0.05)$ in any of the metabolites, the paraxanthine:caffeine ratio, or the metabolite:caffeine ratio between groups. Correlations showed no relationship between the caffeine metabolite ratio and performance improvements. 


\section{Discussion}

In the present study, we observed a significantly higher serum caffeine concentration one hour after supplementation in the $\mathrm{C}$ allele carriers compared with the AA homozygotes. This could be due to decreased rates of caffeine metabolism in this population. However, it should also be realized that there were no differences in the concentrations of the metabolites of caffeine, or the metabolites:caffeine ratio in the blood. It is possible that, because samples were taken from the blood, that metabolites were bound to the A1 adenosine receptors and immeasurable through this technique. While the higher serum caffeine levels and/or faster metabolism could be hypothesized to influence the ergogenic effects of caffeine, we did not observe a caffeine $\mathrm{x}$ genotype interaction in this study. Skinner et al previously observed that matching the timing of exercise performance with peak post-ingestion levels of caffeine does not influence the ergogenic effect. Thus, in the current study, the polymorphism could have affected metabolism without influencing subsequent performance (15).

Unlike prior studies from this laboratory $(12,16)$, we did not observe a genetic influence on the ergogenic effect of caffeine. Womack et al observed that caffeine doubled the average 40km time trial improvement in AA homozygotes versus $\mathrm{C}$ allele carriers (16). In contrast, Pataky et al observed a "likely" larger improvement with caffeine supplementation for the C allele carriers over the AA homozygotes in a $3 \mathrm{~km}$ time trial using magnitude based inferences (12). In the current study, caffeine improved performance in AA homozygotes by an average of

11 seconds, versus 4 seconds in $\mathrm{C}$ allele carriers. That we did not observe a significant difference between the genetic groups may speak to a lack of power in the present study as the sample size in the current study and in the Algrain et al study $(\mathrm{N}=20)$ were less than those reported for the Womack et al and Pataky et al studies ( $\mathrm{N}=35$ and $\mathrm{N}=38$ respectively). There were differences in statistical method between the two studies done previously in the Human Performance Lab at James Madison University. Womack et al used traditional statistics, while Pataky et al used 
magnitude based inferences $(12,16)$. Both studies saw a genotype effect within their respective statistical methods, but when both sets of data were analyzed using traditional statistics, only Womack et al showed a genotype x caffeine interaction, making our results similar to the traditional statistics results of Pataky et al, with no genotype by caffeine interaction $(12,16)$. Our results also corroborate the findings of Algrain et al, who found no differences in performance between genotypes during a 15-minute cycling performance test (1). Supplementation varied between studies, as Algrain et al used caffeine gum and pill ingestion used in the current study (1). Furthermore, unlike the present study, Algrain et al did not observe a significant main effect for caffeine, while there was a performance effect with caffeine supplementation in the current study.

It is worthwhile to explore potential reasons for the equivocal findings from the studies on this topic. In addition to the potential sample size issues, there exists the possibility that the genetic influence on caffeine supplementation is only evident in studies in which a large effect size from caffeine occurs. Womack et al observed a $4.9 \%$ improvement in AA homozygotes in the $40 \mathrm{~km}$ time trial ( 3.7 minute improvement) and $1.8 \%$ improvement in $\mathrm{C}$ allele carriers ( 1.3minute improvement), which appears to be larger than the effects noted by Pataky et al consisting of a possible improvement in performance of $2.0 \% \pm 4.0 \%$ in $\mathrm{A} / \mathrm{C}$ heterozygotes and $1.0 \% \pm 3.2 \%$ in AA homozygotes $(12,16)$. Algrain et al observed minimal improvements in power output between genotypes $(\mathrm{AA}$ homozygotes $=0.02 \% ; \mathrm{C}$ allele carriers $=0.03 \%)(1)$. In the current study, we observed a $2.2 \%$ improvement in $3 \mathrm{~km}$ time trial. The shorter duration trials may contribute to these conflicting results, as Doherty and Smith (6) showed that longer duration trials had significantly larger effect sizes with caffeine supplementation. It is reasonable to expect that the genetic influence on the variance in the ergogenic benefit of caffeine will be more pronounced when there is a greater effect of caffeine. However, we cannot definitively make this conclusion from the available research. 
Training status may have also influenced our findings and previous studies. Our subjects ranged from recreationally trained, active males, to trained cyclists. While Womack et al, studied competitively trained male cyclists, Pataky et al studied recreationally trained males and females. Algrain et al studied males and females of "modest fitness" $(1,12,16)$. Skinner et al found that trained subjects had lower peak caffeine concentrations than untrained subjects at the same dosage, suggesting that caffeine is metabolized faster in trained subjects (14). Fifty percent of the AA homozygotes in the current study consisted of trained cyclists, whereas $58 \%$ of the $\mathrm{C}$ allele carriers were trained. Due to the similar distribution between groups, training status likely did not affect our findings.

Limitations of this study include small effect size and small sample size. Further research is necessary in order to determine the true impact of the CYP1A2 polymorphism and its effect on both caffeine metabolism and the ergogenic effects of caffeine. Future studies should employ both expanded sample sizes and protocols designed to maximize effect size in order to gain full perspective of the effects that the polymorphism may have on caffeine metabolism and cycling performance. Results of this study seem to corroborate the differences in metabolism between the two genetic groups ( $\mathrm{C}$ allele carriers having slower caffeine metabolism over AA homozygotes) with larger caffeine concentrations in the former group. However, with no differences in metabolites or metabolite ratio between groups, rate of metabolism is impossible to report. Furthermore, no influence of the CYP1A2 -163 C>A polymorphism on the ergogenic effect of caffeine on $3 \mathrm{~km}$ cycling performance was evident. 


\section{Manuscript References}

1. Algrain HA, Thomas RM, Carrillo AE, et al. The Effects of a Polymorphism in the Cytochrome P450 CYP1A2 Gene on Performance Enhancement with Caffeine in Recreational Cyclists. Journal of Caffeine Research.

2. Collomp K, Ahmaidi S, Chatard J, Audran M, Prefaut C. Benefits of caffeine ingestion on sprint performance in trained and untrained swimmers. Eur J Appl Physiol Occup Physiol. 1992; 64(4):377-80.

3. Cornelis MC, A El-Sohemy, and H Campos. Genetic polymorphism of CYP1A2 increases risk of myocardial infarction. J Med Genet. 2004;41:758-762.

4. Cornelis MC, El-Sohemy A, Campos H. Genetic polymorphism of CYP1A2 increases the risk of myocardial infarction. J Med Genet. 2004; 41(10):758-62.

5. Doherty M. The effects of caffeine on the maximal accumulated oxygen deficit and short-term running performance. Int J Sport Nutr. 1998; 8:95-104.

6. Doherty M, Smith PM. Effects of caffeine ingestion on exercise testing: a meta-analysis. Int J Sport Nutr Exerc Metab. 2004; 14(6):626-46.

7. Fredholm BB. Adenosine, Adenosine Receptors and the Actions of Caffeine*. Pharmacol Toxicol. 1995; 76(2):93-101.

8. Ganio MS, Klau JF, Casa DJ, Armstrong LE, Maresh CM. Effect of caffeine on sport-specific endurance performance: a systematic review. J Strength Cond Res. 2009; 23(1):315-24.

9. Graham TE. Caffeine and exercise. Sports medicine. 2001; 31(11):785-807.

10. Hallström H, Melhus H, Glynn A, Lind L, Syvänen A, Michaëlsson K. Coffee consumption and CYP1A2 genotype in relation to bone mineral density of the proximal femur in elderly men and women: a cohort study. Nutr Metab (Lond). 2010; 7(1):12.

11. Han X, Ou-Yang D, Lu P, et al. Plasma caffeine metabolite ratio (17X/137X) in vivo associated with G-2964A and C734A polymorphisms of human CYP1A2. Pharmacogenetics and Genomics. 2001; 11(5):429-35.

12. Pataky MA, Womack CJ, Sauders Michael J, et al. Caffeine and 3-km Cycling Performance: Effects of Mouth Rinsing, Genotype, and Time of Day. SJMSS. 2015.

13. Sachse C, Brockmöller J, Bauer S, Roots I. Functional significance of a C $\rightarrow$ A polymorphism in intron 1 of the cytochrome P450 CYP1A2 gene tested with caffeine. Br J Clin Pharmacol. 1999; 47(4):445-9.

14. Skinner TL, Jenkins DG, Leveritt MD, et al. Factors influencing serum caffeine concentrations following caffeine ingestion. Journal of Science and Medicine in Sport. 2014; 17(5):516-20. 
15. Skinner TL, Jenkins DG, Taaffe DR, Leveritt MD, Coombes JS. Coinciding exercise with peak serum caffeine does not improve cycling performance. Journal of Science and Medicine in Sport. 2013; 16(1):54-9.

16. Womack CJ, Saunders MJ, Bechtel MK, et al. The influence of a CYP1A2 polymorphism on the ergogenic effects of caffeine. J Int Soc Sports Nutr. 2012; 9(1):7. 


\section{Figure Legend}

Figure 1. Mean differences between groups in $3 \mathrm{~km}$ time trial

Figure 2. Shows individual $3 \mathrm{~km}$ performances with placebo supplementation (x-axis) and caffeine supplementation (y-axis) for both groups. 
Table 1: Comparison of caffeine, paraxanthine (PX), theophylline (TP), and theobromine (TB), paraxanthine:caffeine ratio, and metabolites:caffeine between both genetic groups.

* Significantly greater than the AA homozygote group $(\mathrm{p}<0.05)$

\begin{tabular}{ccccccc}
\hline & Caffeine ppm & PX ppm & TP ppm & TB ppm & PX:CAF & Met:CAF \\
\hline $\begin{array}{c}\text { AA Homozygotes } \\
(\mathrm{n}=8)\end{array}$ & $11.65 \pm 1.79$ & $0.78 \pm 0.48$ & $0.24 \pm 2.94$ & $0.06 \pm 0.19$ & $0.067 \pm 0.04$ & $0.030 \pm 0.02$ \\
$\begin{array}{c}\text { C Allele Carriers } \\
(\mathrm{n}=12)\end{array}$ & $14.17 \pm 1.82 *$ & $0.78 \pm 0.81$ & $0.28 \pm 2.94$ & $0.24 \pm 0.26$ & $0.074 \pm 0.12$ & $0.038 \pm 0.05$ \\
Total & $13.17 \pm 2.83$ & $0.78 \pm 0.70$ & $0.26 \pm 2.94$ & $0.15 \pm 0.25$ & $0.071 \pm 0.09$ & $0.035 \pm 0.04$ \\
\hline
\end{tabular}




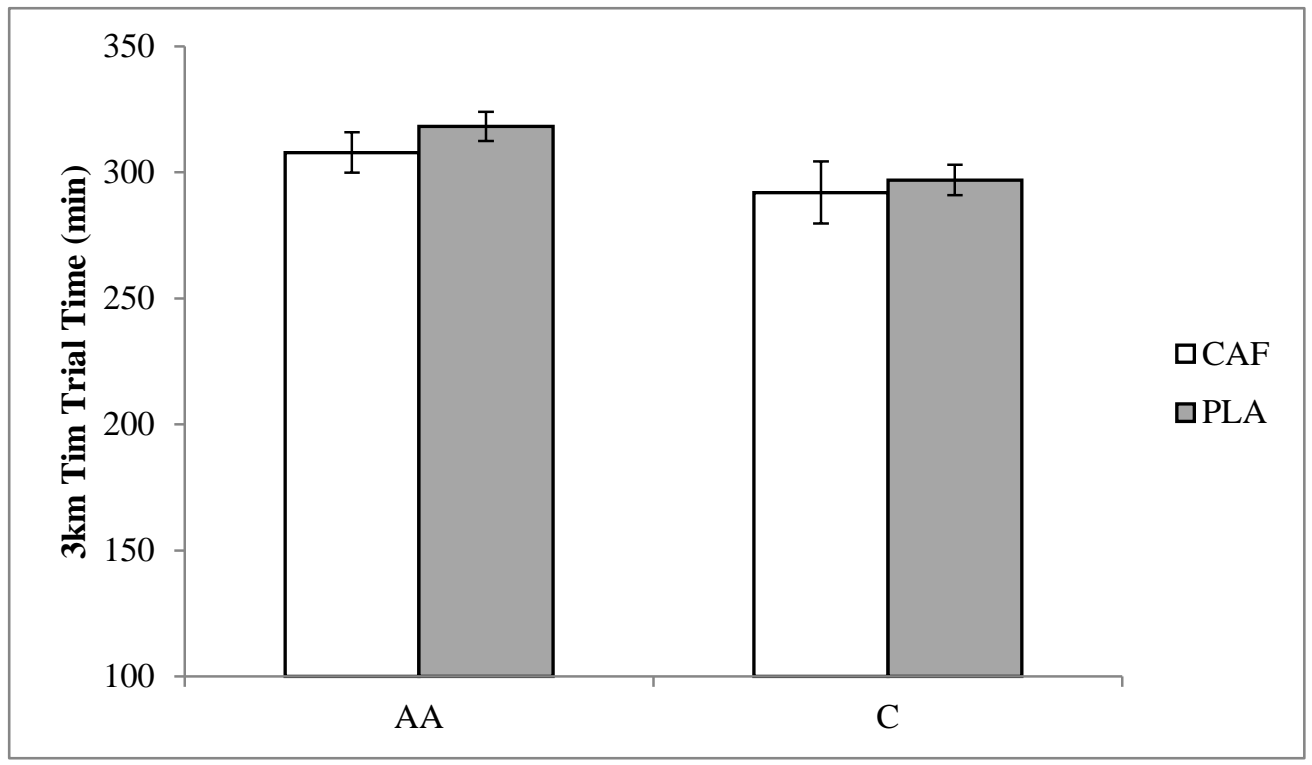




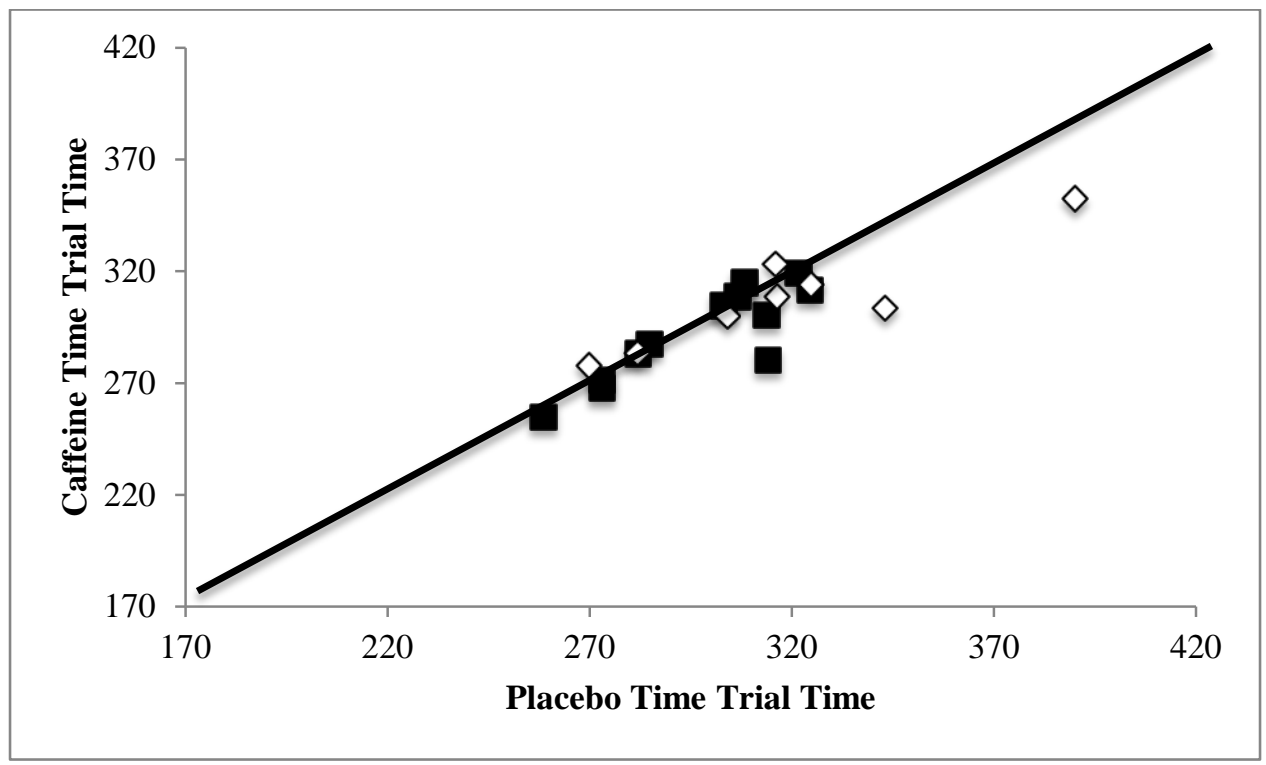




\section{Appendices}

\section{James Madison University}

Department of Kinesiology

Consent for Investigative Procedure

I, hereby agree on

(date) to participate in the research project conducted by Christopher J. Womack, Ph.D., Nicholas D. Luden, Ph.D., James Boyett, and Gabe Giersch from James Madison University titled The Effect of Genetics, Training Status, and Time-of-day Consumption on the Ergogenic Properties of Caffeine.

The purpose of this study is to determine whether or not genetics influences the effects of caffeine supplementation on performance. Additionally, this study aims to determine whether trained individuals benefit more from caffeine supplementation than untrained during cycling and muscular strength performance. The final purpose of this study is to determine whether the time of day affects whether caffeine is beneficial for cycling performance.

\section{Subject Responsibility}

I understand that I will undergo the following testing in the study:

This study consists of seven separate exercise tests performed on both on a muscle strength device and a stationary bike (cardiovascular fitness test, two familiarization tests, and four $3 \mathrm{~km}$ time trial tests). All testing will occur in Godwin Hall, room 209, on the campus of James Madison University. You will also be asked about lifestyle behaviors such as smoking and physical activity and complete dietary and physical activity records. The total time commitment is estimated to be less than 10 hours over the course of 4-6 weeks.

\section{Pre-testing 1 (60 $\mathrm{min})$ :}

After completing this consent form and the health history screening, if you meet the inclusion criteria for the study, researchers will measure your height and body weight.

You will then be asked to perform a maximal cardiovascular fitness test to determine your peak oxygen consumption $\left(\mathrm{VO}_{2 \max }\right)$. You will be asked to ride a stationary bike at an initial workload that is 'fairly easy'. The workload will then be increased every two minutes until exhaustion is reached, determined by either: 1 ) your request to stop due to fatigue, or 2 ) inability to maintain a cadence of $\geq 50$ revolutions per minute. You will be verbally encouraged to continue to obtain 
an accurate measurement of $\mathrm{VO}_{2 m a x}$. To access oxygen consumption, you will need to breathe through a mouthpiece/breathing apparatus which collects expired air throughout the test (1015 minutes).

\section{Familiarization Trials ( $\mathrm{n}=2 ; 30$ minutes each):}

On two occasions, you will be asked to perform peak skeletal muscle function testing and a 3$\mathrm{km}$ cycling practice trial on a stationary bike. You will warm-up with a 5 minute treadmill test at $3.5 \mathrm{mph}$, followed by a strength test. This will consist of two warm-up repetitions followed by two maximal exertion isokinetic peak torque measurements at 30, 120, and 240 degrees/sec. One set consists of two sub-maximal repetitions immediately followed by two maximal repetitions, with sixty seconds of rest between two sets at the same velocity. Once all exertions are completed at a given velocity, 60 seconds of rest will be given before proceeding to the next velocity. After strength testing is complete, you will move to a stationary bicycle to complete the 3-km time trial. You will be encouraged to treat the time trial like a competition.

\section{Experimental Trials $(n=4 ; 120$ minutes each):}

You will report to the laboratory 60 minutes prior to exercise testing. You will rest in a seated position for 5 minutes, after which a blood sample will be obtained for measurement of caffeine/caffeine metabolite levels (one of the samples will also be used to extract DNA for genotyping). Immediately following the blood draw, you will ingest either placebo or caffeine capsules, after which you will wait for $\sim 60$ minutes in the laboratory until exercise testing. Immediately prior to exercise testing, a second blood sample will be obtained for the measurement of caffeine/caffeine metabolite levels. Following the blood draw, you will complete the peak muscle function test and 3-km time trial described above.

\section{Supplementation Protocol:}

No supplementation will be given during the familiarization trials. You will be randomly assigned a treatment order. Treatments will be: 1 . Placebo capsule containing flour administered $1 \mathrm{hr}$ prior to exercise at 8:00am 2. Caffeine capsule containing $6 \mathrm{mg} / \mathrm{kg}$ bodyweight caffeine administered $1 \mathrm{hr}$ prior to exercise at 8:00am 3. Placebo capsule containing flour administered $1 \mathrm{hr}$ prior to exercise at 6:00pm 4. Caffeine capsule containing $6 \mathrm{mg} / \mathrm{kg}$ bodyweight caffeine administered $1 \mathrm{hr}$ prior to exercise at 6:00pm.

\section{Dietary and Exercise Controls:}

You will be asked to record food intake 24 hours prior to the first familiarization trial. You will then be given a copy of the dietary log and asked to replicate food intake for 24 hours prior for each subsequent trial. Additionally, you will be asked to abstain from alcohol and caffeine 
consumption for 24 hours prior to testing in all trials. Additionally, you will be asked to arrive at the laboratory in a fasted state (no food intake within the past 4 hours). Finally, you will be asked to refrain from heavy exercise for 48 hours prior to testing, as well as record any physical activity during the 48 hours prior to testing. You will be asked to maintain consistent physical activity habits before all trials.

\section{DNA Sampling:}

We will extract a sample of your DNA from one of your blood samples. DNA and blood samples will be stored in our laboratory freezer for at least 3 years to allow us to conduct follow-up studies in the event that new discoveries are made related to DNA and caffeine metabolism. Your sample will be coded so that nobody except the primary investigators can identify which sample is yours. The DNA testing will involve determining sequences of DNA for specific genes that are related to caffeine metabolism. We will not use this DNA for any other purpose. The results of this genetic testing will only be available to the primary investigator and you. These results will not be made public and will be stored in a locked file cabinet.

\section{Risks/Benefits:}

\section{Skeletal Muscle Function}

The risks of muscle function testing include soreness from exertion 24-48 hours post and potential lightheadedness or loss of consciousness if correct form is not utilized. You will be instructed in correct form and breathing techniques prior to testing.

\section{$\underline{\text { Cardiovascular Exercise (3-km Time Trial and VO }} 2$ max test)}

According to the American College of Sports Medicine's Guidelines for Exercise Testing and Prescription, the risk associated with heavy exercise for individuals categorized as "low risk" is very minimal, and physician supervision is not necessary. The conditions that the exercise sessions are to take place are likely safer than the typical exercise environments of the subjects. If you do not meet ACSM criteria for "low risk", you will not be allowed to participate in the study. In the unlikely event of cardiac or other complications during exercise, an emergency plan is in place. This includes immediate access to a phone to call emergency personnel. In addition, at least one of the listed investigators will be present during the exercise sessions, and all are CPR certified.

\section{Blood Sampling}

The risks of blood sampling using venipuncture include possible mild bruising, and the risk of transfer of blood-borne pathogens, as well as possible risks of infection or skin irritation. These risks are considered to be minimal, and all safety precautions for handing blood samples will be 
followed according to OSHA protocols, including: investigators will wear latex gloves at all times during blood sampling and testing. A sharps container lined with a biohazard bag will be used for all sharp objects involved in the blood sampling; all other materials (i.e. gloves, gauze pads, etc.) used during the sampling will be put in a separate waste disposal unit lined with a biohazard bag. All investigators who will be involved in blood draws (and handling of blood) have been trained in these phlebotomy techniques, and completed JMU blood-borne pathogen training. The total amount of blood obtained during this study is approximately $24 \mathrm{ml}$. For reference, this amount is $\sim 6 \%$ of a can of soda, or $5 \%$ of the amount given when donating blood in a single session (approximately 1 pint, or $473 \mathrm{ml}$ ).

\section{Caffeine Ingestion}

The risks and side effects associated with caffeine supplementation include: rapid heart rate, elevated blood pressure, headache, nausea, vomiting, restlessness, agitation, and anxiet

\section{Performance incentive:}

The top 5 trained performers (fastest finishing placebo time, use of caffeine would necessitate an unfair advantage to possible genetic responders) will be entered into a drawing to win $\$ 150$. Trained individuals in the top 6-10 placebo time will be entered into a drawing to win $\$ 75$. An identical incentive method will be used for the untrained subjects ( $1 \$ 150$ and $1 \$ 75$ ).

\section{Confidentiality}

The results of this research will be presented at conferences and published in exercise science journals. The results of this project will be coded in such a way that your identity will not be attached to the final form of this study. The researcher retains the right to use and publish non-identifiable data. However, you can ask that your data be removed from the study at any point prior to presentation and publication. While individual responses are confidential, aggregate data will be presented representing averages or generalizations about the responses as a whole. All data will be stored in a secure location accessible only to the researcher. Final aggregate results will be made available to you upon request.

\section{Participation \& Withdrawal}

Your participation is entirely voluntary. You are free to choose not to participate. Should you choose to participate, you can withdraw at any time without consequences of any kind. Your right to withdraw includes the right to request that your DNA and blood samples be discarded at any time. You should be aware that the DNA sample is subject to court subpoena. To dispose of your samples, your samples will be rinsed down a chemical drain in our laboratory or will be disposed of in a biohazard container. Again, your sample will not be identifiable without the coding document that will be locked away in a filing cabinet. 


\section{Questions}

You may have questions or concerns during the time of your participation in this study, or after its completion. If you have any questions about the study, contact Nicholas D. Luden, Ph.D. at ludennd@jmu.edu or by phone at 540-568-4068.

\section{Giving of Consent}

I have read this consent form and I understand what is being requested of me as a participant in this study. I freely consent to participate. I have been given satisfactory answers to my questions. The investigator provided me with a copy of this form. I certify that I am at least 18 years of age.

$\overline{\text { Name of Participant (Printed) }} \quad$ Name of Researcher(s) (Printed)

Name of Participant (Signed)

Date
Name of Researcher(s) (Signed)

Date

For questions about your rights as a research subject, you may contact the chair of JMU's Institutional Review Board (IRB). Dr. David Cockley, (540) 568-2834, cocklede@jmu.edu. 


\section{AHA/ACSM Health/Fitness Facility Pre-participation Screening Questionnaire}

Assess your health status by marking all true statements

\section{History}

You have had:

a heart attack

heart surgery

cardiac catheterization

coronary angioplasty (PTCA)

pacemaker/implantable cardiac

defibrillator/rhythm disturbance

heart valve disease

heart failure

heart transplantation

congenital heart disease

If you marked any of these statements in this section, consult your physician or other appropriate health care provider before engaging in exercise. You may need to use a facility with a medically qualified

\section{Symptoms}

You experience chest discomfort with exertion You experience unreasonable breathlessness You experience dizziness, fainting, or blackouts You take heart medications

\section{Other Health Issues} You have diabetes You have asthma or other lung disease You have burning or cramping sensation in your lower legs when walking short distances You have musculoskeletal problems that limit your physical activity You have concerns about the safety of exercise You take prescription medication(s)

\section{Cardiovascular risk factors}

You are a man older than 45 years

You smoke, or quit smoking within the previous 6 months Your blood pressure is $>140 / 90 \mathrm{mmHg}$ You do not know your blood pressure You take blood pressure medication Your blood cholesterol level is $>200 \mathrm{mg} / \mathrm{dl}$

You do not know your cholesterol level You have a close blood relative who had a heart attack or heart surgery before age 55 (father or brother) or age 65 (mother or sister) 
You are physically inactive (i.e. you get $<30$ minutes of physical activity on at least 3 days of the week) You are $>20$ pounds overweight

None of the above

You should be able to exercise safely without consulting your physician or other appropriate health care provider in a self-guided program or almost any facility that meets your exercise program needs. 
Subject Prescreening Information \& Caffeine Habits

Age: years

Height Weight

Typical Exercise Habits over the Past 3-6 Months:

Average number of days of cycling per week

Average number of hours of cycling per week

Briefly describe your cycling habits over the past 3-6 months:

Average number of days of resistance exercise/weight lifting per week

Average number of hours of resistance exercise/weight lifting per week

Briefly describe your resistance training habits over the past 3-6 months:

Do you have a muscle or joint injury/condition that precludes the completion of the cycling or muscle function protocol? If yes, please explain.

Are you allergic to wheat?

Do you have gluten intolerance?

Are you allergic to latex? 


\section{Physical Activity Records}

\begin{tabular}{|c|c|c|c|}
\hline ubject \# & Trial \# & Date:_ & \\
\hline Date & Type of Exercise Performed & $\begin{array}{l}\text { Duration of Exercise } \\
\text { (minutes) }\end{array}$ & $\begin{array}{l}\text { Intensity of Exercise } \\
\text { (use scale below) }\end{array}$ \\
\hline & & & \\
\hline & & & \\
\hline & & & \\
\hline & & & \\
\hline & & & \\
\hline & & & \\
\hline & & & \\
\hline & & & \\
\hline
\end{tabular}

\begin{tabular}{ll}
\multicolumn{2}{l}{ Intensity Scale } \\
6 & \\
7 & Very, very light \\
8 & \\
9 & Very light \\
10 & \\
11 & Fairly light \\
12 & \\
13 & Somewhat hard \\
14 & \\
15 & Hard \\
16 & \\
17 & Very hard \\
18 & \\
19 & Very, very hard
\end{tabular}




\section{Hour Diet Record}

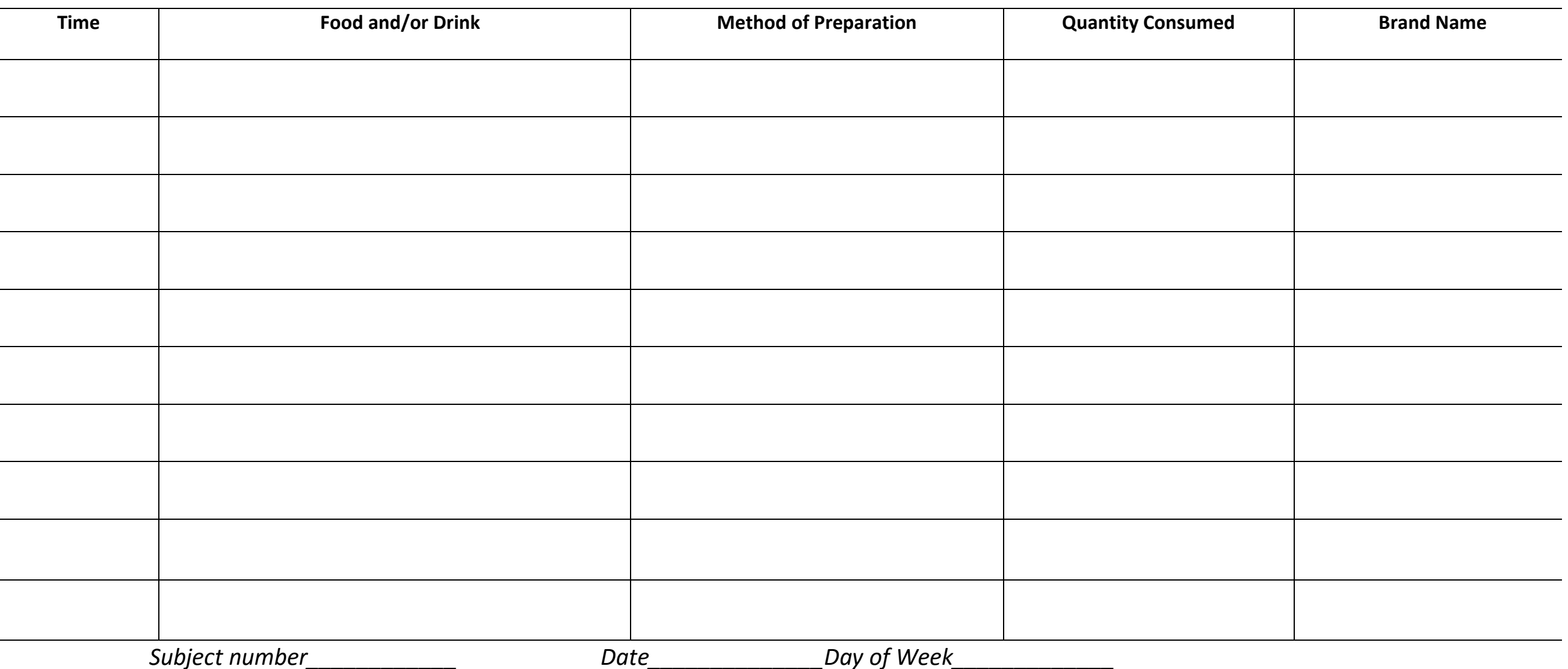

Adapted From: Lee RD, Nieman DC. Nutritional Assessment. 2nd ed. United States of America: 


\section{References}

1. Algrain HA, Thomas RM, Carrillo AE, et al. The Effects of a Polymorphism in the Cytochrome P450 CYP1A2 Gene on Performance Enhancement with Caffeine in Recreational Cyclists. Journal of Caffeine Research.

2. Anselme F, Collomp K, Mercier B, Ahmaidi S, Prefaut C. Caffeine increases maximal anaerobic power and blood lactate concentration. Eur J Appl Physiol Occup Physiol. 1992; 65(2):188-91.

3. Bridge C, Jones M. The effect of caffeine ingestion on $8 \mathrm{~km}$ run performance in a field setting. J Sports Sci. 2006; 24(4):433-9.

4. Burke LM. Caffeine and sports performance. Applied physiology, nutrition, and metabolism. 2008; 33(6):1319-34.

5. Carr A, Dawson B, Schneiker K, Goodman C, Lay B. Effect of caffeine supplementation on repeated sprint running performance. J Sports Med Phys Fitness. 2008; 48(4):472-8.

6. Cornelis MC, A El-Sohemy, and H Campos. Genetic polymorphism of CYP1A2 increases risk of myocardial infarction. J Med Genet. 2004;41:758-762.

7. Cornelis MC, El-Sohemy A, Kabagambe EK, Campos H. Coffee, CYP1A2 genotype, and risk of myocardial infarction. JAMA. 2006; 295(10):1135-41.

8. Cureton KJ, Warren GL, Millard-Stafford ML, Wingo JE, Trilk J, Buyckx M. Caffeinated sports drink: ergogenic effects and possible mechanisms. Int J Sport Nutr Exerc Metab. 2007; 17(1):35.

9. Dodd SL, Herb RA, Powers SK. Caffeine and exercise performance. Sports medicine. 1993; 15(1):1423.

10. Doherty M, Smith P. Effects of caffeine ingestion on rating of perceived exertion during and after exercise: a meta-analysis. Scand J Med Sci Sports. 2005; 15(2):69-78.

11. Doherty M. The effects of caffeine on the maximal accumulated oxygen deficit and short-term running performance. Int J Sport Nutr. 1998; 8:95-104.

12. Doherty M, Smith PM, Davison RR, Hughes MG. Caffeine is ergogenic after supplementation of oral creatine monohydrate. Med Sci Sports Exerc. 2002; 34(11):1785-92.

13. Fredholm BB. Adenosine, Adenosine Receptors and the Actions of Caffeine*. Pharmacol Toxicol. 1995; 76(2):93-101.

14. Ganio MS, Klau JF, Casa DJ, Armstrong LE, Maresh CM. Effect of caffeine on sport-specific endurance performance: a systematic review. J Strength Cond Res. 2009; 23(1):315-24.

15. Glaister M, Howatson G, Abraham C, et al. Caffeine supplementation and multiple sprint running performance. Medicine Science in Sports Exercise. 2008; 40(10):1835.

16. Graham TE. Caffeine and exercise. Sports medicine. 2001; 31(11):785-807. 
17. Graham TE, Hibbert E, Sathasivam P. Metabolic and exercise endurance effects of coffee and caffeine ingestion. J Appl Physiol (1985). 1998; 85(3):883-9.

18. Graham TE, Spriet LL. Metabolic, catecholamine, and exercise performance responses to various doses of caffeine. J Appl Physiol (1985). 1995; 78(3):867-74.

19. Greer F, Friars D, Graham TE. Comparison of caffeine and theophylline ingestion: exercise metabolism and endurance. J Appl Physiol (1985). 2000; 89(5):1837-44.

20. Hallström H, Melhus H, Glynn A, Lind L, Syvänen A, Michaëlsson K. Coffee consumption and CYP1A2 genotype in relation to bone mineral density of the proximal femur in elderly men and women: a cohort study. Nutr Metab (Lond). 2010; 7(1):12.

21. Han X, Ou-Yang D, Lu P, et al. Plasma caffeine metabolite ratio (17X/137X) in vivo associated with G-2964A and C734A polymorphisms of human CYP1A2. Pharmacogenetics and Genomics. 2001; 11(5):429-35.

22. Hawke TJ, Allen DG, Lindinger MI. Paraxanthine, a caffeine metabolite, dose dependently increases [Ca(2+)](i) in skeletal muscle. J Appl Physiol (1985). 2000; 89(6):2312-7.

23. Jackman M, Wendling P, Friars D, Graham TE. Metabolic catecholamine, and endurance responses to caffeine during intense exercise. J Appl Physiol (1985). 1996; 81(4):1658-63.

24. Kalow W, Tang B. Use of caffeine metabolite ratios to explore CYP1A2 and xanthine oxidase activities. Clinical Pharmacology \& Therapeutics. 1991; 50(5-1):508-19.

25. McNaughton LR, Lovell R, Siegler J, Midgley A, Moore L, Bentley DJ. The effects of caffeine ingestion on time trial cycling performance. International journal of sports physiology and performance. $2008 ; 3(2): 157$.

26. Palatini P, Ceolotto G, Ragazzo F, et al. CYP1A2 genotype modifies the association between coffee intake and the risk of hypertension. J Hypertens. 2009; 27(8):1594-601.

27. Pataky MA, Womack CJ, Sauders Michael J, et al. Caffeine and 3-km Cycling Performance: Effects of Mouth Rinsing, Genotype, and Time of Day. SJMSS. 2015.

28. Perera V, Gross AS, McLachlan AJ. Caffeine and paraxanthine HPLC assay for CYP1A2 phenotype assessment using saliva and plasma. Biomedical Chromatography. 2010; 24(10):1136-44.

29. Sachse C, Brockmöller J, Bauer S, Roots I. Functional significance of a C $\rightarrow$ A polymorphism in intron 1 of the cytochrome P450 CYP1A2 gene tested with caffeine. Br J Clin Pharmacol. 1999; 47(4):445-9.

30. Schneiker KT, Bishop D, Dawson B, Hackett LP. Effects of caffeine on prolonged intermittent-sprint ability in team-sport athletes. Med Sci Sports Exerc. 2006; 38(3):578-85.

31. Skinner TL, Jenkins DG, Leveritt MD, et al. Factors influencing serum caffeine concentrations following caffeine ingestion. Journal of Science and Medicine in Sport. 2014; 17(5):516-20. 
32. Skinner TL, Jenkins DG, Taaffe DR, Leveritt MD, Coombes JS. Coinciding exercise with peak serum caffeine does not improve cycling performance. Journal of Science and Medicine in Sport. 2013; 16(1):54-9.

33. Spriet LL. Caffeine and performance. Int J Sport Nutr. 1995; 5:S84-.

34. Tarnopolsky MA. Effect of caffeine on the neuromuscular system-potential as an ergogenic aid. Applied physiology, nutrition, and metabolism. 2008; 33(6):1284-9.

35. Womack CJ, Saunders MJ, Bechtel MK, et al. The influence of a CYP1A2 polymorphism on the ergogenic effects of caffeine. J Int Soc Sports Nutr. 2012; 9(1). 